\title{
Issues and opportunities associated with using manatee mortality data to evaluate the effectiveness of manatee protection efforts in Florida
}

\author{
C. Scott Calleson* \\ Florida Fish and Wildlife Conservation Commission, Imperiled Species Management Section, 620 South Meridian Street, \\ Tallahassee, FL 32399, USA
}

\begin{abstract}
Protection zones to reduce risks to Florida manatees Trichechus manatus latirostris associated with boat operation have been in place since the 1990s or earlier in most areas considered important for the species. Despite the relatively long period of time protections have been in place, evaluating the effectiveness of these efforts has proven to be difficult. This paper discusses manatee mortality data, which is one of the most long-term sources of data available for analysis, and some of the difficulties associated with using these data to evaluate effectiveness. It then explores the concept of using differences in rates of change in mortality during three $10 \mathrm{yr}$ periods as an evaluation metric. Rates were calculated for the state of Florida as a whole and for Treatment and No Treatment groups, with the Treatment group including all counties where comprehensive protection zones have been established. The only rates of change that were statistically different from one another were for boat-related deaths, both statewide and for the Treatment group, between the 1981-1990 and 2001-2010 periods. Statewide, the average rate of increase fell from 11.2 to $1.0 \% \mathrm{yr}^{-1}$, while, within the Treatment group, the rate fell from 12.4 to $1.2 \% \mathrm{yr}^{-1}$. These results provide evidence that protection efforts have likely helped to reduce boat-related mortality risks; however, the analysis does not account for some uncertainties associated with the mortality data, and the confidence intervals are fairly wide. Additional research and analyses should be pursued to account for these issues and also to consider risks related to non-lethal manatee-boat collisions.
\end{abstract}

KEY WORDS: Florida manatee - Trichechus manatus latirostris $\cdot$ Boat speed zones $\cdot$ Mortality · Risk reduction · Effectiveness

\section{INTRODUCTION}

The Florida subspecies of the West Indian manatee Trichechus manatus latirostris has been legally protected in the state of Florida since 1893, with the early state laws aimed mostly at prohibiting hunting or harassment. In 1978, with passage of the Florida Manatee Sanctuary Act (currently in 379.2431(2), Florida Statutes), legal protection and state authority expanded to include protecting manatees from other human-related impacts, including those caused by

${ }^{*}$ Corresponding author: scott.calleson@myfwc.com boats. Federal protection was also expanded in the late 1960s and 1970s with the passage of several federal laws, including the Endangered Species Act (1973) and the Marine Mammal Protection Act (1972).

Boat-related mortality is the single greatest impediment to manatee population growth and resilience (Runge et al. 2007). For this reason, one of the primary actions taken to improve protection has been the establishment of comprehensive manatee protection zones in areas that are important for manatees. Other actions have also been taken, including re-

(C) The author 2014. Open Access under Creative Commons by Attribution Licence. Use, distribution and reproduction are unrestricted. Authors and original publication must be credited. 
views of permits for new or expanded boating facilities, the development and implementation of manatee protection plans in many counties in Florida, and extensive outreach and education efforts designed to improve public awareness and promote safer boat operation.

Manatee protection zones have been established by the state of Florida (Florida Fish and Wildlife Conservation Commission, FWC), as well as the United States Fish and Wildlife Service (USFWS) and various local governments. Both the federal recovery plan for manatees (USFWS 2001) and the state Manatee Management Plan (FWC 2007) call for the establishment and management of these zones as an important component of overall protection efforts. Most manatee protection zones limit the maximum allowable speed at which boats may be operated. The first zones were established in the late 1970s, but most zones were created in the 1990s. Calleson \& Frohlich (2007) describe the conceptual basis for this risk-reduction method.

Manatee protection issues are often contentious and frequently have very vocal supporters and opponents (Haubold 2012). The process used to create manatee protection zones, by necessity, seeks to find a balanced solution that provides conservation benefits for this species but is also supported by most stakeholders and the general public. As with almost any issue, the ability to make reasoned policy decisions and obtain support for those decisions is greatly improved when the supporting data are strong. Of similar importance, however, is the ability to evaluate actions after they have been implemented in order to assess whether they are achieving the desired goals. Evaluating the effectiveness of manatee protection zones has always been an important task, but quantifying effectiveness has proven to be elusive.

The administrative rules of the FWC state that manatee protection zones are necessary if their absence will likely result in injury or death to manatees, harassment of manatees, or destruction of essential manatee habitat. So, a zone or combination of zones is effective if it accomplishes or helps to accomplish these goals. Because the primary purpose of the vast majority of manatee protection zones is to address issues related to boat collision risk, it makes sense to focus on this purpose first when trying to assess whether zones have been effective.

Unfortunately, even restricting the evaluation to this one purpose still leaves a very difficult question to answer. How does one determine if zones have reduced manatee injuries and deaths from boat col- lisions? In an ideal world, it would be known how many manatees use an area and how this number changes over time, as well as how many injuries and how many deaths are caused by boat collisions over time (which would allow the injury rate and death rate to be calculated). Assuming no other variables (such as changes in the way manatees use the system or the number of boats being operated in the system), zones would be effective if the rates decreased or at least stabilized after the zones had been put in place.

In practice, most of the information needed to make the above assessment is either not known or is uncertain. Currently, there are no statistical estimates of manatee abundance at statewide or county levels (O'Shea et al. 2001, FWC 2007). At the regional level, Craig \& Reynolds (2004) assessed manatee abundance and population trends between 1982 and 2001 along the Atlantic coast using cold season aerial survey data; however, similar estimates for other regions have not been made, nor has an updated analysis been completed for the Atlantic coast. The minimum size of the manatee population can be estimated based on statewide synoptic surveys that are flown most winters, but these surveys do not produce a population estimate, nor are the results comparable across years, so changes in population size over time cannot be calculated from these counts (O'Shea et al. 2001, Reep \& Bonde 2006, FWC 2007). Synoptic surveys also produce counts that are meaningful primarily at the statewide or management unit (regional) scale as opposed to a county level. Beyond population estimates, other factors are also difficult to assess. For instance, sub-lethal injuries to manatees from boat collisions appear to be much more common than lethal injuries (O'Shea et al. 2001, Lightsey et al. 2006, Calleson \& Frohlich 2007); however, the number and rate of occurrence of sub-lethal injuries are largely unknown, in part because few collisions are reported, and in fewer still is the manatee found in order to determine if injuries occurred. Even the number of deaths is not known with certainty, because some carcasses likely go undetected or unreported. And even given a specific number of total deaths, the number of deaths from boat collisions is not known with certainty, because the cause of death cannot always be established (Ackerman et al. 1995, O'Shea et al. 2001, Runge et al. 2007).

A few studies (Laist \& Shaw 2006, Keith et al. 2008, C. Fonnesbeck unpubl. data) have evaluated the effectiveness of manatee protection zones in site-specific locations and found evidence supporting the benefits of zones. Laist \& Shaw (2006) and 
C. Fonnesbeck (unpubl. data) examined changes in boat-related mortality to evaluate specific zones in a portion of one county. To date, no studies have been published that investigated the effectiveness of manatee protection efforts from a statewide perspective, although several (Ackerman et al. 1995, Wright et al. 1995) have analyzed mortality data and evaluated trends at statewide and regional scales without relating the results to effectiveness of prior actions. This paper discusses manatee mortality data and some of the difficulties associated with using the data to evaluate effectiveness. It also explores the idea of using differences in rates of change as an evaluation metric. If manatee protection efforts have been effective, and all other factors remain the same, then one would expect the rate of change in boat-related mortality to decrease after zones have been established.

\section{METHODS}

\section{Manatee mortality data}

Statewide data on manatee (Trichechus manatus latirostris) mortality have been collected since 1974 . Recorded information includes date and location of recovery, cause of death (when it can be determined), and a variety of morphometric and other biological data. The carcass recovery program and mortality database are currently administered by the FWC. Prior to July 1985, these responsibilities were handled by the USFWS (FWC 2007).

Reporting and recovery of carcasses is opportunistic in the sense that there is no systematic monitoring or searching for carcasses; carcasses can be reported by anyone, including waterfront residents and guests, boaters, and law enforcement personnel. A $24 \mathrm{~h}$ tollfree hotline for reporting carcasses (and other resource issues) has been maintained by the state of Florida since at least the early 1980s (Bonde et al. 1983). All reports of carcasses are investigated to the fullest extent possible. Most carcasses (typically about $70 \%$ ) are collected and taken to the FWC's Fish and Wildlife Research Institute Marine Mammal Pathobiology Laboratory (MMPL; built in 1992) for a detailed necropsy (FWC 2007). Less detailed field necropsies are performed on some carcasses if it is impractical to transport the carcass back to the MMPL facility. A relatively small number of carcasses (typically $<2-3 \%$ ) are verified but not recovered for examination. In 2011, for example, 453 deaths were recorded, with 14 of these verified but not recovered; 314 were taken to
MMPL for necropsy, and 125 field necropsies were performed (FWC unpubl. data). Annual summaries of mortality and other information are available online at http://myfwc.com/research/manatee/rescuemortality-response/.

Cause of death is assigned to 1 of 9 categories: boat collision, flood gate or navigation lock, other human, perinatal, cold stress, other natural, verified but not recovered, undetermined (too decomposed for evaluation), and undetermined (inconclusive findings). Bonde et al. (1983), Lightsey et al. (2006), and the FWC (2007) provide information on the necropsy process. A description of each of the cause-of-death categories is available online at the website given in the previous paragraph.

Ackerman et al. (1995), Wright et al. (1995), and O'Shea et al. (2001) discuss some of the potential biases in the mortality data that complicate trend analysis. As previously mentioned, some deaths likely go undetected or unreported, particularly in less intensively used areas, such as the Everglades (Runge et al. 2007). The number of deaths that go undetected is unknown but probably small given the large number of people on and around most waterways and the fact that carcasses (other than calves) are large and relatively easy to spot in most cases. It is possible that the detection rate was lower in the past, particularly in the 1970s and early 1980s, when there were fewer people on and around the water and public awareness of the need to report carcasses was lower. Even within a given time period, detection rates may vary by location given differences in waterway characteristics (e.g. depth, water clarity, and quantity and types of shoreline vegetation) and the number of people using the areas (Ackerman et al. 1995, Wright et al. 1995).

Another potential bias relates to the deaths that are verified but not recovered and the deaths assigned to the undetermined categories, since some unknown proportion of these deaths could have been caused by boat collisions. Ackerman et al. (1995) suggest that improved diagnostic procedures have generally decreased the proportion of deaths assigned to the undetermined categories (and increased the number assigned to the cold stress and other natural categories), but that they have probably not substantially increased the proportion assigned as boat-related because such injuries are often distinctive even on decomposed carcasses. The greatest likelihood of 'missed' boatrelated deaths would occur for manatees that suffered internal (blunt force) trauma without obvious external injuries, particularly if a carcass was only 
verified and not recovered. There were 261 deaths recorded as verified but not recovered between 1974 and January 2011 (FWC unpubl. data). This represents $3.2 \%$ of all recorded mortality over this period. About $25 \%$ of the unrecovered carcasses (67) occurred in 2010 during extremely cold weather that killed several hundred manatees, with 56 of the unrecovered deaths recorded in the Everglades portion of Monroe County. Another $27 \%$ of the unrecovered carcasses (71) occurred during 5 other years between 1996 and 2009 when cold weather and/or red tide killed unusually high numbers of manatees. It is likely that a large percentage of these unrecovered deaths was related to these mortality events.

Although not as much of a concern for macro-scale analyses, another important issue is the relationship between the carcass recovery location and the actual location where a manatee died or where a collision with a boat occurred. The manatee mortality database records the location where a carcass was recovered. In most cases, this cannot be assumed to be the location where the manatee died because carcasses can be moved downstream by water flow in some waterways and can also drift as a result of tide and wind. In the case of boat-related deaths, manatees may not be killed immediately, so they may continue to move on their own after the collision, sometimes for extended periods. When sufficient information is available to make a determination, boat-related deaths are classified as either acute or chronic. A death is classified as acute if evidence suggests death occurred immediately or within approximately $24 \mathrm{~h}$ after the collision (Lightsey et al. 2006). Available evidence does not always allow for this distinction to be made, and acute versus chronic may not have been noted in all cases where it could be determined. In recent years, more emphasis has been put on investigating and noting this distinction whenever possible (i.e. there may be more instances in the earlier years where a death was acute, but this was not noted in the mortality database). For fine-scale analyses, even limiting analysis to only acute deaths may not be sufficient because even a few hours of movement or drift could be significant.

Although the mortality dataset clearly has limitations and deficiencies, it is one of the most readily available sources of data and it has the important qualities of being a long-term database that can be analyzed at a variety of scales. Ackerman et al. (1995) noted that assessing trends in mortality data can provide important information and 'may reveal areas where protection is effective.'

\section{Rates of change as an evaluation metric}

Changes in the absolute number of boat-related deaths or total deaths over time is not a valuable metric, because the size of the manatee population at any given time is not known with much certainty and likely has changed over time. Statewide, as well as at the management unit level, available information suggests that the size of the manatee population has increased over the last few decades, with the rate and timing of increases varying to some degree among the 4 management units (FWC 2007). Because of the dynamic nature of the size of the manatee population, rather than using changes in the absolute number of deaths, an alternative is to examine the extent to which the rates of change in the number of deaths have altered over time. For the present analysis, rates of change were calculated for boat-related deaths alone and for all other death categories combined, with 3 different $10 \mathrm{yr}$ periods examined. The 'PreZone' period (1981-1990) can be described as the period when the need for protection zones was being recognized but before many zones had been adopted; the 'Zone Adoption' period (1991-2000) as the period when comprehensive zones were initially adopted in most of the counties considered important for manatees; and the 'Post-Adoption' period (2001-2010) as the period after comprehensive zones had been adopted in most of the counties considered important for manatees.

Rates of change were calculated for the state as a whole and for Treatment and No Treatment groups. The Treatment group included all counties where comprehensive zones have been established $(n=19)$, regardless of when the zones were established. The No Treatment group included all other counties $(\mathrm{n}=48)$. Fig. 1 shows the locations of the counties in the Treatment and No Treatment groups, as well as the carcass recovery locations for all boat-related manatee deaths recorded between 1981 and 2010. As in Ackerman et al. (1995), rates of change were calculated using exponential regression (with the analysis run using the number of deaths +1 to avoid having any zero values). Confidence intervals were calculated at the 95 and $90 \%$ levels.

The Treatment group included the 19 counties where manatee protection needs were evaluated on a countywide basis, and state-designated manatee protection zones were subsequently established throughout all or most of the county. Adoption of comprehensive zones ranged from as early as 1990 to as late as 2004 . Implementation of the zones (i.e. when markers were posted on the water to notify boaters about the zones) 


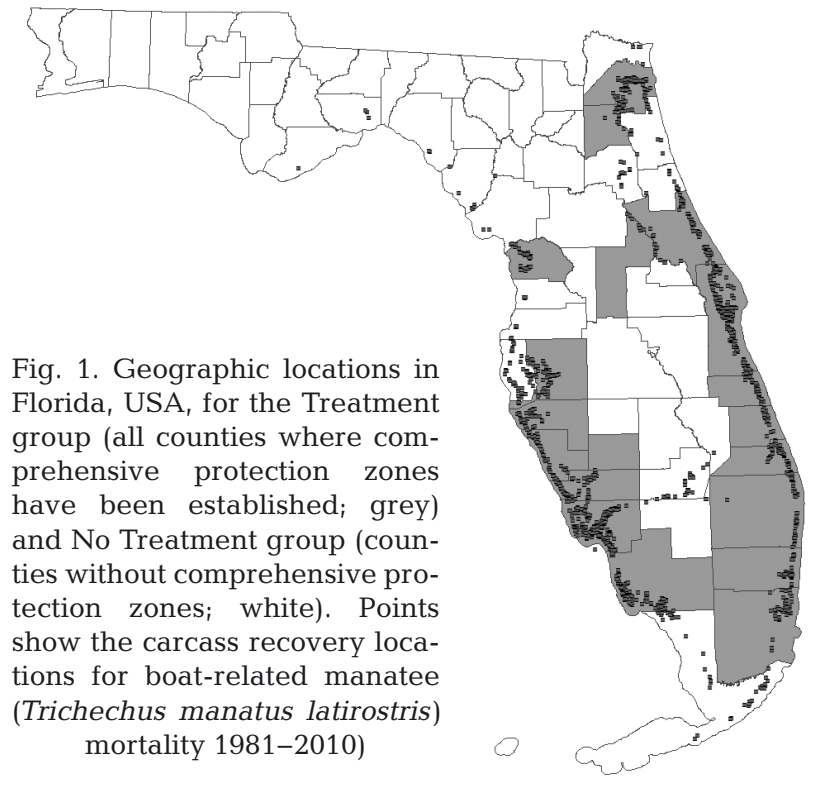

typically required 12 to 18 mo after adoption. The counties included in this group were (year when zones were adopted is given in parentheses): Brevard (1992 - most of county; 2002 - entire county); Broward (1993); Charlotte (2002); Citrus (1992); Clay (2000included as part of the rule for Duval County); Collier (1990); DeSoto (2002 — included as part of the rule for Charlotte County); Duval (1992); Hillsborough (2004); Indian River (1992); Lake (1991 — included as part of the rule for Volusia County); Lee (1999); Manatee (2004); Martin (1990); Miami-Dade (1991); Palm Beach (1990); St. Lucie (1994); Sarasota (1992); and Volusia (1991). FWC (2007) provides a summary of rule making by county and also includes information on the amount of regulated area and the amount of coastal and inland water in each county (excluding nearshore waters of the Atlantic Ocean and Gulf of Mexico and landlocked waters that do not have a navigable connection to coastal waters). The state-designated manatee protection zones in these 19 counties, in total, cover about $24 \%$ of the coastal and inland waters in these counties. These counties combined account for about half of the coastal and inland waters in the state.

Eight of the 48 counties in the No Treatment group (Flagler, Hernando, Levy, Marion, Pinellas, Putnam, Seminole, and St. Johns) have state-designated manatee protection zones in a small portion of the county, most of which were established as part of the rules for counties in the Treatment group. Manatee protection zones cover $<5 \%$ of the coastal and inland water in any of these counties. Twenty-one of the counties in the No Treatment group have very little or no coastal or inland water that is accessible to manatees. No manatee deaths in any category were recorded in 23 of the No Treatment counties through 2010; no boatrelated deaths were recorded in 31 of these counties.

\section{RESULTS}

A total of 7554 manatee (Trichechus manatus latirostris) deaths was recorded in Florida between 1981 and 2010 , with just under $23 \%$ of the deaths (1728) attributed to collisions with boats (Table 1). The 19

Table 1. Manatee (Trichechus manatus latirostris) mortality by group (Statewide; Treatment: counties with comprehensive protection zones; No Treatment: counties without comprehensive protection zones), cause (boats, all others), and year (1981-2010) in the 3 periods

\begin{tabular}{|c|c|c|c|c|c|c|}
\hline \multirow[t]{2}{*}{ Year } & \multicolumn{2}{|c|}{ Statewide } & \multicolumn{2}{|c|}{ Treatment } & \multicolumn{2}{|c|}{ No Treatment } \\
\hline & Boats & $\begin{array}{c}\text { All } \\
\text { others }\end{array}$ & Boats & $\begin{array}{c}\text { All } \\
\text { others }\end{array}$ & Boats & $\begin{array}{c}\text { All } \\
\text { others }\end{array}$ \\
\hline \multicolumn{7}{|c|}{ Pre-Zone period } \\
\hline 1981 & 24 & 92 & 21 & 67 & 3 & 25 \\
\hline 1982 & 20 & 94 & 16 & 87 & 4 & 7 \\
\hline 1983 & 15 & 66 & 12 & 55 & 3 & 11 \\
\hline 1984 & 34 & 94 & 30 & 80 & 4 & 14 \\
\hline 1985 & 33 & 86 & 31 & 74 & 2 & 12 \\
\hline 1986 & 33 & 89 & 32 & 71 & 1 & 18 \\
\hline 1987 & 39 & 75 & 39 & 67 & 0 & 8 \\
\hline 1988 & 43 & 90 & 39 & 78 & 4 & 12 \\
\hline 1989 & 50 & 118 & 42 & 108 & 8 & 10 \\
\hline 1990 & 47 & 159 & 44 & 135 & 3 & 24 \\
\hline $\begin{array}{r}\text { Totals } \\
\text { (1981 }\end{array}$ & $\begin{array}{c}338 \\
-1990)\end{array}$ & 963 & 306 & 822 & 32 & 141 \\
\hline \multicolumn{7}{|c|}{ Zone Adoption period } \\
\hline 1991 & 53 & 121 & 52 & 106 & 1 & 15 \\
\hline 1992 & 38 & 125 & 34 & 109 & 4 & 16 \\
\hline 1993 & 35 & 111 & 31 & 88 & 4 & 23 \\
\hline 1994 & 49 & 143 & 44 & 115 & 5 & 28 \\
\hline 1995 & 42 & 159 & 36 & 136 & 6 & 23 \\
\hline 1996 & 60 & 355 & 56 & 331 & 4 & 24 \\
\hline 1997 & 54 & 188 & 48 & 169 & 6 & 19 \\
\hline 1998 & 66 & 165 & 58 & 135 & 8 & 30 \\
\hline 1999 & 82 & 187 & 69 & 154 & 13 & 33 \\
\hline 2000 & 78 & 194 & 66 & 167 & 12 & 27 \\
\hline $\begin{array}{c}\text { Totals } \\
(1991\end{array}$ & $\begin{array}{c}557 \\
-2000)\end{array}$ & 1748 & 494 & 1510 & 63 & 238 \\
\hline \multicolumn{7}{|c|}{ Post-Adoption period } \\
\hline 2001 & 81 & 244 & 77 & 195 & 4 & 49 \\
\hline 2002 & 95 & 210 & 82 & 177 & 13 & 33 \\
\hline 2003 & 73 & 307 & 60 & 262 & 13 & 45 \\
\hline 2004 & 69 & 207 & 57 & 182 & 12 & 25 \\
\hline 2005 & 80 & 316 & 67 & 277 & 13 & 39 \\
\hline 2006 & 92 & 325 & 86 & 259 & 6 & 66 \\
\hline 2007 & 73 & 244 & 62 & 207 & 11 & 37 \\
\hline 2008 & 90 & 247 & 80 & 209 & 10 & 38 \\
\hline 2009 & 97 & 332 & 81 & 303 & 16 & 29 \\
\hline 2010 & 83 & 683 & 78 & 519 & 5 & 164 \\
\hline $\begin{array}{l}\text { Totals } \\
(2001\end{array}$ & $\begin{array}{c}833 \\
-2010)\end{array}$ & 3115 & 730 & 2590 & 103 & 525 \\
\hline $\begin{array}{l}\text { Totals } \\
\text { (all) }\end{array}$ & 1728 & 5826 & 1530 & 4922 & 198 & 904 \\
\hline
\end{tabular}


counties comprising the Treatment group accounted for $6452(85 \%)$ of the recorded deaths and 1530 $(89 \%)$ of the boat-related deaths. Fig. 2 shows the number of boat-related deaths for the Treatment and No Treatment groups by year.

The rate of increase for boat-related deaths, both statewide and for the Treatment group, declined for each successive period, while the rate of increase for all other deaths combined rose for each successive period (Table 2). The rate of increase for boat-related deaths for the No Treatment group rose sharply dur- ing the middle period but was essentially stable during the other 2 periods. The rate of increase for all other deaths combined for the No Treatment group rose for each successive period. Fig. 3 shows the boatrelated deaths for each of the 3 periods, with exponential regression lines superimposed (dashed lines). Because the Treatment group accounted for such a large proportion of the manatee mortality recorded in the state, the rates of change for statewide mortality and the Treatment group were expected to have similar values and show similar patterns.

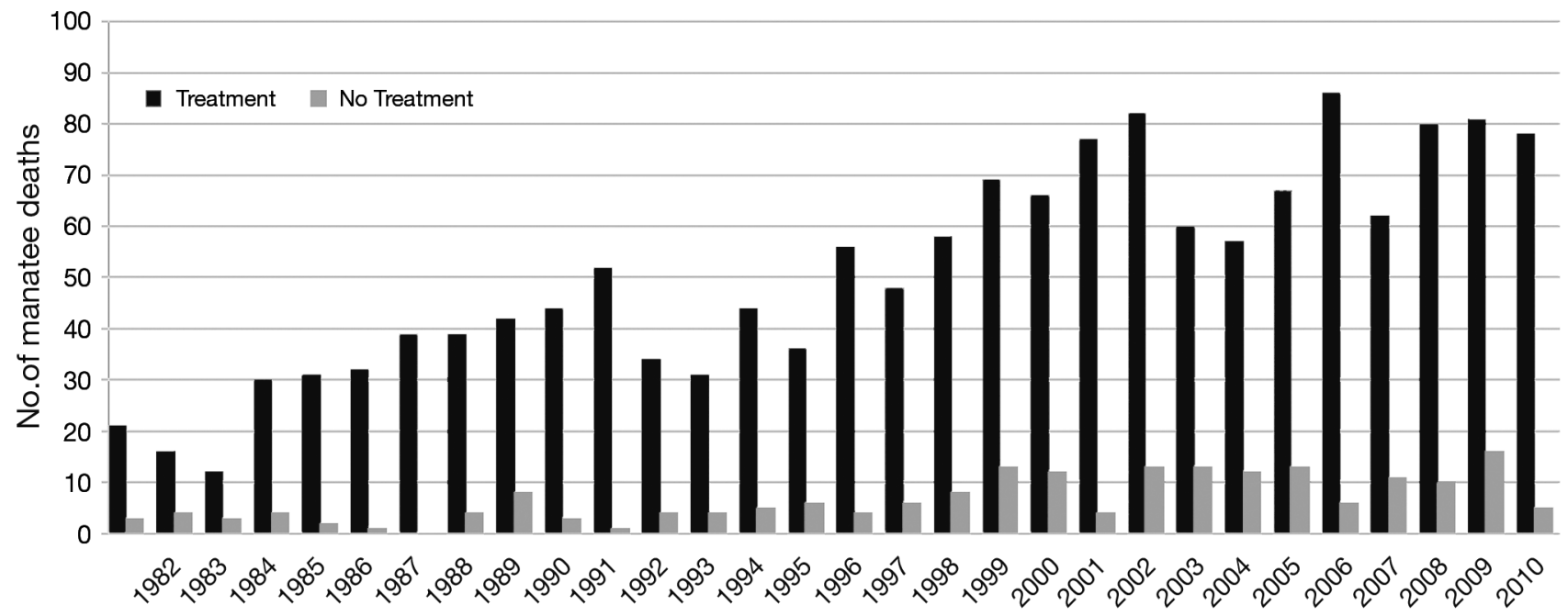

Fig. 2. Boat-related manatee (Trichechus manatus latirostris) mortality by group (Treatment and No Treatment; for details see Fig. 1) and year (1981-2010)

Table 2. Manatee (Trichechus manatus latirostris) mortality. Results of rates of change analysis by period in the 3 groups (Statewide; Treatment: counties with comprehensive protection zones; No Treatment: counties without comprehensive protection zones). Rates are the average annual rate of increase over each period and are significantly different from one another if the confidence intervals do not overlap. Mean: mean number of deaths per year; range: range over the $10 \mathrm{yr}$ period

\begin{tabular}{|c|c|c|c|c|c|c|c|c|c|c|}
\hline & \multirow{3}{*}{$\begin{array}{c}\text { Rate } \\
(\%)\end{array}$} & \multicolumn{4}{|c|}{ Boat-related deaths } & \multirow{3}{*}{$\begin{array}{c}\text { Rate } \\
(\%)\end{array}$} & \multicolumn{4}{|c|}{ All other deaths } \\
\hline & & Confidenc & ce intervals & Mean & Range & & Confidenc & e intervals & Mean & Range \\
\hline & & $95 \%$ & $90 \%$ & & & & $95 \%$ & $90 \%$ & & \\
\hline \multicolumn{11}{|c|}{ Statewide group } \\
\hline $1981-1990$ & 11.2 & $5.6-17.1$ & $6.7-15.9$ & 33.8 & $15-50$ & 4.6 & $-0.8-10.2$ & $0.2-9.1$ & 96.3 & $66-159$ \\
\hline $1991-2000$ & 7.8 & $3.1-12.8$ & $4.0-11.8$ & 55.7 & $35-82$ & 6.6 & $-0.8-12.8$ & $0.6-13.0$ & 174.8 & $111-355$ \\
\hline $2001-2010$ & 1.0 & $-2.0-4.2$ & $-1.4-3.6$ & 83.3 & $69-97$ & 7.5 & $0.0-15.5$ & $1.4-13.9$ & 311.5 & $207-683$ \\
\hline \multicolumn{11}{|c|}{ Treatment group } \\
\hline $1981-1990$ & 12.4 & $5.8-19.5$ & $7.1-18.1$ & 30.6 & $12-44$ & 5.5 & $0.1-11.2$ & $1.2-10.1$ & 82.2 & $55-135$ \\
\hline $1991-2000$ & 6.7 & $1.4-12.3$ & $2.4-11.2$ & 49.4 & $31-69$ & 6.6 & $-1.9-15.9$ & $-0.3-14.0$ & 151.0 & $88-331$ \\
\hline $2001-2010$ & 1.2 & $-2.6-5.1$ & $-1.9-4.4$ & 73.0 & $57-86$ & 7.4 & $0.7-14.5$ & $2.0-13.0$ & 259.0 & $177-519$ \\
\hline \multicolumn{11}{|c|}{ No Treatment group } \\
\hline 1981-1990 & 0.0 & $-14.7-17.5$ & $-12.2-13.9$ & 3.2 & $0-8$ & 0.7 & $-9.5-12.0$ & $-7.6-9.7$ & 14.1 & $7-25$ \\
\hline $1991-2000$ & 17.9 & $10.2-26.0$ & $11.7-24.4$ & 6.3 & $1-13$ & 6.3 & $1.6-11.2$ & $2.5-10.3$ & 23.8 & $15-49$ \\
\hline $2001-2010$ & 0.5 & $-10.2-12.5$ & $-8.2-10.1$ & 10.3 & $4-16$ & 6.7 & $-6.4-21.6$ & $-4.0-18.5$ & 52.5 & $25-164$ \\
\hline
\end{tabular}


Boat-related manatee mortality (1981-1990)

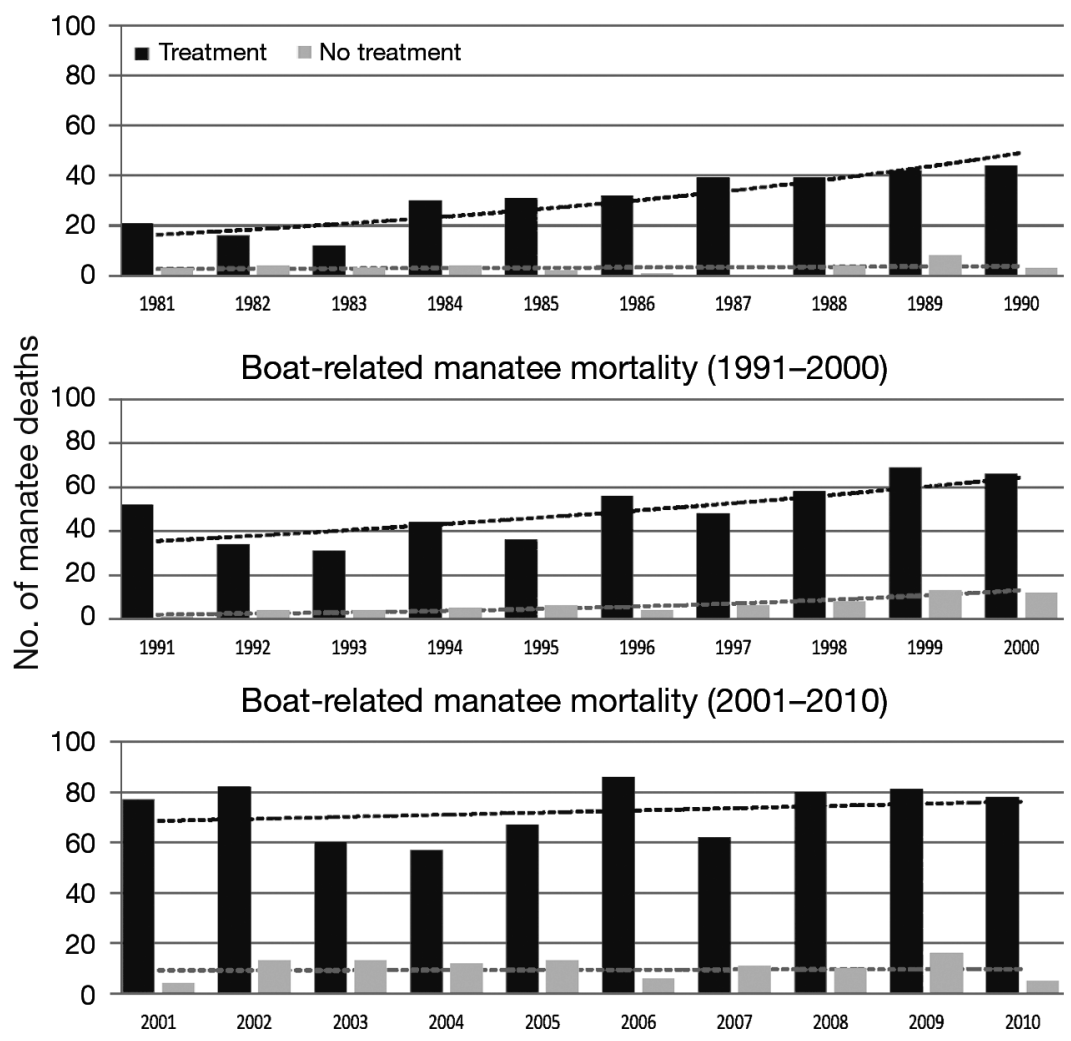

Fig. 3. Boat-related manatee (Trichechus manatus latirostris) mortality by group (Treatment and No Treatment; for details see Fig. 1) and period (19811990, 1991-2000, 2001-2010). Dashed lines depict the respective exponential regression lines

rates of increase for boat-related deaths, both statewide and for the Treatment group, between the Pre-Zone (19811990) and Post-Adoption (2001-2010) periods. Statewide, the average rate of increase fell from 11.2 to $1.0 \% \mathrm{yr}^{-1}$, while, within the Treatment group, the rate fell from 12.4 to $1.2 \% \mathrm{yr}^{-1}$.

\section{DISCUSSION}

The importance of evaluating the effectiveness of manatee (Trichechus manatus latirostris) protection zones has long been recognized, for conservation, political, and socio-economic reasons. From the conservation perspective, measuring effectiveness is important because it can show whether and to what extent zones are producing positive results and whether more or less needs to be done to achieve conservation goals. From the political and socioeconomic perspectives, quantifying effectiveness is necessary to maintain long-term support from the general public and stakeholders.

Unfortunately, quantifying the effectiveness of manatee protection zones is extremely difficult, even when the

The ability to draw statistical inferences from these results is limited by the fact that the small sample sizes ( $\mathrm{n}=10$ for each grouping) and frequently substantial inter-annual variations in the numbers of deaths resulted in relatively wide confidence intervals. This is especially true for the No Treatment group, where the annual number of deaths was often in the single digits and a difference of even a single death represented a sizeable percentage of the total. For example, the rate of increase in boat-related deaths statewide fell from an average rate of $11.2 \% \mathrm{yr}^{-1}$ during the Pre-Zone period (1981-1990) to $7.8 \% \mathrm{yr}^{-1}$ during the Zone Adoption period (1991-2000), but the confidence intervals for these rates overlap (even at the $90 \%$ level) (Table 2). Although close, even the rise in the rate of increase in boat-related deaths in the No Treatment group from $0.0 \%$ (Pre-Zone period) to $17.9 \%$ (Zone Adoption period) was not statistically significant because of the extremely wide confidence intervals.

The only rates of change that were statistically different from one another at the $95 \%$ level were the evaluation is limited to considering only manatee deaths caused by boats. Estimating a true mortality rate (i.e. deaths as a proportion of the population) is not possible without estimates of the size of the population at various points in time. The size of the manatee population currently cannot be estimated with statistical confidence. The most recent synoptic survey (in 2014) produced a statewide minimum count of 4824 . The highest minimum count to date (in 2010) was 5077 (FWC unpubl. data). Trends in population size are not known with certainty either, but the overall population likely has grown based on survival rates and population growth rates estimated for each of the 4 management units. The FWC Manatee Management Plan (FWC 2007) reports estimated annual growth rates (through the 1999-2000 timeframe) of $6.2 \%$ for the Upper St. Johns River unit, $4.0 \%$ for the Northwest unit, $3.7 \%$ for the Atlantic unit, and $-1.1 \%$ for the Southwest unit. Updated estimates are currently being developed for all units, with early indications being that the Southwest unit may be faring more similarly to the Atlantic unit. The maximum 
rate at which the manatee population could potentially grow is in the range of 7 to $8 \% \mathrm{yr}^{-1}\left(\mathrm{O}^{\prime}\right.$ Shea et al. 2001, Reep \& Bonde 2006, Marsh et al. 2011). Since a true mortality rate cannot be estimated, an alternative is to compare the rates of change in the number of deaths during different periods. If the population is growing, and assuming the risks remain the same, it would be reasonable to expect the number of deaths to increase at a similar rate to that of the population.

An analysis of the rates of change indicates that the rate of increase in boat-related deaths has likely slowed over time. Available information suggests the manatee population has grown, with the average statewide rate of increase possibly in the range of $3 \%$ or more per year (although it should be noted that unusually high mortality from cold weather, red tide, and other causes in 2010 and subsequent years may have substantially reduced the population gains). The decline in the rate of increase in boat-related deaths cannot be explained simply as a byproduct of population changes. The fact that the changes in the rates of increase in boat-related deaths were so different from those for all other deaths combined supports the conclusion that changes in population growth rates are not the primary cause.

At the same time as the rate of increase in boatrelated deaths was slowing, the number of boats registered in Florida increased dramatically and changes in hull designs and propulsion systems allowed more boats to be operated at higher speeds in shallow water. Statewide, the number of boat registrations increased by $82 \%$ between 1981 and 2010 (from 512551 to 933 885), with the number of registrations peaking at 1027043 in 2007 (Florida Department of Highway Safety and Motor Vehicles unpubl. data). Even if the manatee population had not grown, it would be reasonable to expect the rate of increase in boat-related deaths to have risen given the large increase in the number of boats in Florida. The fact that it did not, suggests other factors were operating to mitigate boat-related mortality. One of the most significant actions taken to mitigate risks during this time was the establishment of comprehensive manatee protection zones in most of the areas considered important for manatees, so it is reasonable to view these results as providing evidence that there has likely been a positive effect from the zones (along with other protection efforts and increased public awareness).

These results provide evidence at the statewide level that manatee protection efforts likely have helped to reduce boat-related mortality risks for manatees; however, the rates of change calculations do not account for some uncertainties associated with the mortality data (e.g. issues related to carcass detection rates, verified but unrecovered carcasses, etc.), and the confidence intervals for the rates of change are fairly wide. It will be difficult to account for these uncertainties, especially retrospectively, but it would be beneficial if additional analyses could be undertaken that account for these issues and allow more robust statistical analysis. Inferences about effectiveness at the statewide level have the strongest statistical power if based on analysis of the statewide data, although analysis of just the Treatment group produces similar results because this group has accounted for close to $90 \%$ of all boatrelated manatee mortality in the state. Analysis of either dataset would be appropriate from a policy perspective since the counties in the Treatment group have been chosen based on the goal of protecting manatees where needed to ensure their longterm viability throughout the state. Use of this method at finer scales, such as at the county level, is not likely to be useful because of the very wide confidence intervals that would be produced given the relatively small number of deaths that occur in any given county per year and the frequent fluctuations in the number of deaths from year to year. Evidence of this issue can be seen from the results of the analysis of the No Treatment group.

Research on other metrics of effectiveness needs to continue. To fully measure effectiveness, information is also needed to evaluate changes in non-lethal manatee-boat collisions (i.e. injuries rather than mortality). The approach used by Keith et al. (2008), which involves aerial surveys and focal follows of selected manatees, appears to be very promising, but this method may be difficult to apply in many locations because it requires a tremendous amount of effort to collect the site-specific data needed for the assessment. Another promising approach currently being studied (Rycyk et al. 2011) involves tagging manatees with GPS-based telemetry tags that also collect depth and acoustic information. These data can be compared to information collected on boats being operated in the same area to evaluate how manatees respond under different conditions, both when they are inside of protection zones and outside. This research method is also very labor intensive and costly, so it may be difficult to apply in more than a few locations. A third approach currently being developed (Calleson \& Boland 2011) analyzes manatee and boat aerial survey data in a geographic information system to examine the degree of spatial over- 
lap in order to help evaluate the boat-collision risk. Unlike the analysis of rates of change in mortality, which is a statewide assessment, the methods of Keith et al. (2008) and Rycyk et al. (2011) were applied at a very fine scale (i.e. a small portion of a single county), whereas the method of Calleson \& Boland (2011) is applied at a fine scale but with the results used as part of a broader assessment, primarily applied at the county level. One other promising approach (Martin et al. unpubl. data), which is still in the early stages of investigation but which uses case studies for both manatees and right whales, is looking to use a structured decision-making approach to quantify and predict the effects of different management scenarios on both injury and mortality.

Analyses being performed to measure risk as well as effectiveness of protection efforts for other species may also provide methods that can be applied to manatees. Of particular promise is work being done for North Atlantic right whales Eubalaena glacialis related to risks and effectiveness of efforts to reduce whale-ship collisions (Vanderlaan \& Taggart 2007, Fonnesbeck et al. 2008, Vanderlaan et al. 2009, Lagueux et al. 2011, Wiley et al. 2011, Silber \& Bettridge 2012, van der Hoop et al. 2012, Conn \& Silber 2013, Laist et al. 2014). The ability to assess risks for right whales is significantly improved by the availability of detailed information on the numbers, routes, and speeds of large ships moving through right whale habitat. Similar data are not currently available for the hundreds of thousands of boats that operate in manatee habitat, and are unlikely to be available in the future; however, if alternate measures of boat traffic can be developed, similar methodologies may be able to be applied to assess risks to manatees. Work on these and other approaches should continue so that effectiveness as well as risk can be evaluated at a variety of scales. It will also be important for data on zone compliance by boaters (see Shapiro 2001, Gorzelany 2004, 2006) to continue to be collected, because significant levels of non-compliance could have a significant impact on zone effectiveness.

Acknowledgements. I thank Dr. John Reynolds of Mote Marine Laboratory, Dr. Buddy Powell of Sea to Shore Alliance and others, including many current and former FWC staff members, for reviewing earlier versions of this manuscript and providing very helpful comments. I also thank the anonymous reviewers and the editors for their constructive comments and suggestions. Lastly, I thank all of the current and former staff members and volunteers from the FWC and other agencies and organizations who have been involved in the collection and examination of manatee carcasses or the maintenance of the manatee mortality database.

\section{LITERATURE CITED}

Ackerman BB, Wright SD, Bonde RK, Odell DK, Banowetz DJ (1995) Trends and patterns in mortality of manatees in Florida, 1974-1992. In: O'Shea TJ, Ackerman BB, Percival HF (eds) Population biology of the Florida manatee. National Biological Service Information and Technology Report 1, Washington, DC, p 223-258

Bonde RK, O'Shea TJ, Beck CA (1983) Manual of procedures for the salvage and necropsy of carcasses of the West Indian manatee (Trichechus manatus). Report No. PB83-255273, US Department of Commerce, National Technical Information Service, Alexandria, VA

Calleson S, Boland C (2011) Using Geographic Information System (GIS) spatial analysis methods to help evaluate use and boat collision risks for the Florida manatee (Trichechus manatus latirostris). Proc 19th biennial conference on the biology of marine mammals

Calleson CS, Kipp Frohlich R (2007) Slower boat speeds reduce risks to manatees. Endang Species Res 3:295-304

Conn PB, Silber GK (2013) Vessel speed restrictions reduce risk of collision-related mortality for North Atlantic right whales. Ecosphere 4:art43

Craig BA, Reynolds JE (2004) Determination of manatee population trends along the Atlantic coast of Florida using a Bayesian approach with temperature-adjusted aerial survey data. Mar Mamm Sci 20:386-400

> Fonnesbeck CJ, Garrison LP, Ward-Geiger LI, Baumstark RD (2008) Bayesian hierarchical model for evaluating the risk of vessel strikes on North Atlantic right whales in the SE United States. Endang Species Res 6:87-94

FWC (Florida Fish and Wildlife Conservation Commission) (2007) Florida manatee management plan. FWC, Tallahassee, FL. Available at: http://myfwc.com/media/ 415297/Manatee_MgmtPlan.pdf

Gorzelany JF (2004) Evaluation of boater compliance with manatee speed zones along the Gulf coast of Florida. Coast Manage 32:215-226

Gorzelany JF (2006) An assessment of changes in recreational boat traffic resulting from the placement of new speed zones in Lemon Bay, Florida. Final Report submitted to the National Fish and Wildlife Foundation. Technical Report No. 1018, Mote Marine Laboratory, Sarasota, FL

> Haubold EM (2012) Using adaptive leadership principles in collaborative conservation with stakeholders to tackle a wicked problem: imperiled species management in Florida. Hum Dimens Wildl 17:344-356

Keith LW, Taylor CR, Powell JA, Frisch KJ (2008) Evaluation and monitoring of proposed manatee sanctuaries and reserves. Final Report submitted to the US Fish and Wildlife Service by Wildlife Trust, St. Petersburg, FL

> Lagueux KM, Zani MA, Knowlton AR, Kraus SD (2011) Response by vessel operators to protection measures for right whales Eubalaena glacialis in the southeast US calving ground. Endang Species Res 14:69-77

> Laist DW, Shaw C (2006) Preliminary evidence that boat speed restrictions reduce deaths of Florida manatees. Mar Mamm Sci 22:472-479

> Laist DW, Knowlton AR, Pendleton D (2014) Effectiveness of mandatory vessel speed limits for protecting North Atlantic right whales. Endang Species Res 23:133-147

> Lightsey JD, Rommel SA, Costidis AM, Pitchford TD (2006) Methods used during gross necropsy to determine watercraft-related mortality in the Florida manatee (Tri- 
chechus manatus latirostris). J Zoo Wildl Med 37:262-275

Marsh H, O'Shea TJ, Reynolds JE III (2011) Ecology and conservation of the Sirenia: dugongs and manatees. Cambridge University Press, New York, NY

O'Shea TJ, Lefebvre LW, Beck CA (2001) Florida manatees: perspectives on populations, pain, and protection. In: Dierauf LA, Gulland FMD (eds) CRC handbook of marine mammal medicine, 2nd edn. CRC Press, Boca Raton, FL

Reep RL, Bonde RK (2006) The Florida manatee. University Press of Florida, Gainesville, FL

Runge MC, Sanders-Reed CA, Langtimm CA, Fonnesbeck CJ (2007) A quantitative threats analysis for the Florida manatee (Trichechus manatus latirostris). US Geological Survey Open-file Report 2007-1086. www.pwrc.usgs.gov/ resshow/manatee/documents/OFR2007-1086.pdf

Rycyk AM, Deutsch CJ, Barlas ME, Koslovsky SM, Frisch KJ, Nowacek DP (2011) Florida manatee response to vessels: integration of geo-spatial, behavioral, and multisensor data. Proc 19th biennial conference on the biology of marine mammals

Shapiro SL (2001) Assessing boater compliance with manatee speed zones in Florida. Project No. 9322-1602280. Final report submitted to the US Fish and Wildlife Service, St. Petersburg, FL

Silber GK, Bettridge S (2012) An assessment of the final rule to implement vessel speed restrictions to reduce the threat of vessel collisions with North Atlantic right whales.

Editorial responsibility: Helene Marsh, Townsville, Queensland, Australia
US Dept of Commerce, NOAA Tech Memo NMFS-OPR48:1-114

USFWS (US Fish and Wildlife Service) (2001) Florida manatee recovery plan, (Trichechus manatus latirostris), 3rd revision. USFWS, Atlanta, GA

van der Hoop JM, Vanderlaan ASM, Taggart CT (2012) Absolute probability estimates of lethal vessel strikes to North Atlantic right whales in Roseway Basin, Scotian Shelf. Ecol Appl 22:2021-2033

> Vanderlaan ASM, Taggart CT (2007) Vessel collisions with whales: the probability of lethal injury based on vessel speed. Mar Mamm Sci 23:144-156

Vanderlaan ASM, Corbett JJ, Green SL, Callahan JA and others (2009) Probability and mitigation of vessel encounters with North Atlantic right whales. Endang Species Res 6:273-285

> Wiley DN, Thompson M, Pace RM III, Levenson J (2011) Modeling speed restrictions to mitigate lethal collisions between ships and whales in the Stellwagen Bank National Marine Sanctuary, USA. Biol Conserv 144: 2377-2381

Wright SD, Ackerman BB, Bonde RK, Beck CA, Banowetz DJ (1995) Analysis of watercraft-related mortality of manatees in Florida, 1979-1991. In: O'Shea TJ, Ackerman BB, Percival HF (eds) Population biology of the Florida manatee. National Biological Service Information and Technology Report 1:259-268

Submitted: February 5, 2014; Accepted: July 28, 2014

Proofs received from author(s): October 20, 2014 